\title{
NIETZSCHE: LA CREACIÓN DE PERSONAJES PEDAGÓGICOS A PARTIR DE SU CONCEPCIÓN DE IMAGEN DE HOMBRE, CUERPO Y EDUCACIÓN
}

\section{NIETZSCHE: CREATION OF PEDAGOGICAL CHARACTERS FROM HIS CONCEPTION OF BODY AND EDUCATION}

\author{
Andrés Felipe Correa Castaño ${ }^{1}$
}

\section{Resumen}

\begin{abstract}
Este artículo expresa una perspectiva pedagógica sobre la filosofía de Nietzsche desde el método teórico-documental, con el objetivo de hacer una hermenéutica de su concepción de cuerpo y educación, a la luz de las imágenes de hombre (menschebild) provenientes de la antropología pedagógica filosófica². Se problematiza en el artículo la educación como nivelación, cuya finalidad es estandarizar la docencia mediante una tendencia paradójica de la cultura de expansión/reducción. A partir de la interpretación, se plantea como conclusión la formación de docentes partiendo de un proceso de creación de personajes pedagógicos donde se concibe una educación como el proceso creativo que busca la emergencia de fuerzas corporales.
\end{abstract}

Palabras clave: Imagen de hombre, educación, cuerpo, personajes pedagógicos.

Abstract

This paper shows a pedagogical perspective upon Nietzsche's philosophy from a documentary-andtheoretical method. It is in order to perform a hermeneutic conception of body and education focused by man's image from a philosophical educational anthropology (menschenbild). Also problematizes education as grading aimed to standardize teaching through a paradoxical trend of the expansion/ reduction culture. Then a conclusion is given from interpretation as the teacher training based on a process of pedagogical character generation where education is seen as a creative process looking for emergence of a bodily strength.

Keywords: Picture of man, education, body, pedagogical characters.

Fecha de recepción: 18 de mayo de 2012

Fecha de aprobación: 17 de septiembre de 2012

1 Magíster en Motricidad-Desarrollo Humano. Licenciado en Educación Física. Docente e investigador de la Universidad de Antioquia, Medellín, Colombia. Grupo de Investigación: Estudios en Educación Corporal. Correo electrónico: abedel1982@hotmail.com

2 La antropología pedagógica alemana, aunque no han faltado interpretaciones antropológico-culturales de la educación, se ha fundamentado sobre la filosofía. La década de 1950 fue el comienzo de la antropología pedagógica con la publicación de una obra de Derbolav en 1951. En 1958, el filósofo O.F. Bollnow planteó como tema central la antropología pedagógica como un modo de observación para hacer ver las imágenes de hombre en los discursos pedagógicos. 


\section{Educación y cultura}

Nietzsche valora la cultura en que vive como la cultura de la máquina. Esta no moviliza en el hombre más que sus fuerzas inferiores e irreflexivas, no fomenta las ganas de educarse, de hacer las cosas mejor y con más arte. La fuerza creativa le da el paso a la fuerza reproductiva, se impone la técnica, el movimiento repetitivo y la uniformidad.

En El porvenir de nuestras escuelas, Nietzsche (1980) relaciona la cultura con la educación universitaria. Tal relación está mediada por unos intereses de utilidad e igualación de los hombres que desvían los propósitos de las universidades como instituciones culturales. Estos efectos surgen a partir de la tendencia paradójica de promover la ampliación cultural en las universidades, al mismo tiempo que se la restringe a través de unos límites dibujados por el Estado y la economía política.

Por diversas razones, la cultura debe extenderse al círculo más amplio posible: eso es lo que exige la primera tendencia. En cambio, la segunda exige a la propia cultura que abandone sus pretensiones más altas, más nobles y más sublimes, y se ponga al servicio de otra forma de vida cualquiera, por ejemplo, del Estado. Creo haber notado de donde proviene con mayor claridad la exhortación a extender y a difundir lo más posible la cultura. Esa extensión va contenida en los dogmas preferidos de la economía política de esta época nuestra. Conocimiento y cultura en la mayor cantidad posible -producción y necesidades en la mayor cantidad posible-, felicidad en la mayor cantidad posible: esa es la fórmula poco más o menos. En este caso vemos que el objetivo último de la cultura es la utilidad, o, más concretamente, la ganancia, un beneficio en dinero que sea el mayor posible [...] Por eso, el auténtico problema de la cultura consistiría en educar a cuantos hombres 'corrientes' posibles, en el sentido en que se llama 'corriente' a una moneda. (Nietzsche, 1980, p. 57)

Como consecuencia de este tipo de educación orientada por la cultura de la máquina, se redujeron a su mínima expresión las múltiples posibilidades de formación cultural, que apuntaban a proveer al hombre un amplio repertorio de convicciones a partir de las cuales pudiera orientar su existencia, paradójicamente, bajo el imperativo económico-político de ampliar la propia cultura. En segundo término, se redujo el sentido de la cultura a aquellas acciones que nos proveen felicidad y riqueza: felicidad en el sentido cristiano de una ética de la moderación, y riqueza en el sentido capitalista de la acumulación de bienes.

Específicamente, algunos de los efectos generados por la cultura en el ámbito académico son: disminución del tiempo de reflexión sobre los temas tratados, un afán irremediable por obtener resultados, escribir libros carentes de estilo y rigurosidad conceptual, y una tendencia por valorar aquellos esfuerzos que redunden en el aumento de los ingresos.

Otro efecto problemático es la libertad académica en que se mueven todos en las universidades. La independencia del juicio de los estudiantes no encuentra en el profesor un depurador del pensamiento, un estremecedor de los lugares comunes. Su modus operandi es complaciente. No violenta la paz ni el placer del hábito en busca de heridas y sus correspondientes inoculaciones que fortalezcan los instintos de aventura, las aspiraciones a trazarse nuevos horizontes para el pensamiento.

En síntesis, la misión de la universidad apuntó principalmente a la formación de profesionales y de buenas personas de acuerdo a los valores establecidos, y empieza a debilitar la formación cultural cuyo propósito es promover la autonomía a partir de la ampliación de perspectivas. Este último propósito es el que Nietzsche insiste en concebir como la tarea principal de la universidad. Porque la formación cultural le permite al hombre acceder, desde una diversidad de áreas, a una amplia gama de valores, permitiéndole la crítica, la comparación y la selección autónoma de los mismos. En esto consiste la libertad provista por la educación:

Tus verdaderos educadores y formadores te revelan lo que es el genuino sentido originario y la materia básica de tu ser, algo en absoluto susceptible de ser educado ni formado, pero, en cualquier caso, difícilmente accesible, apretado, paralizado: tus educadores no pueden ser otra cosa que tus liberadores. Y éste es el secreto de toda formación: no proporciona prótesis, narices de cera, ni ojos de cristal. Lo que estos dones pueden dar es más bien la mera caricatura de la educación. Porque la educación no es sino liberación. (Nietzsche, 2000b, p. 29)

\section{Imagen de hombre}

La concepción nietzscheana de la educación está íntimamente relacionada con las imágenes de hombre que el autor tiene. Es importante considerar estas imágenes, ya que dan coherencia a la concepción que el autor 
tiene de la educación. Aquellas dan cuenta del modo de pensar, sentir y valorar de un sujeto. Toda pedagogía medianamente consecuente -ya se trate de una praxis coherente o de una teoría argumentativa- lleva inherente, explícita o implícitamente, una idea del hombre, una imagen de lo que es el hombre y de lo que este puede y debe ser.

El hombre nietzscheano es un emancipado del rebaño, de la opinión pública, de la moral vigente. Es un hombre guiado por el sentimiento de la insatisfacción, por la actitud de sospecha y por el desprecio de la comodidad y la pereza.

En La gaya ciencia (2001) nos dirá que el hombre es una balanza que determina el valor de las cosas: "Ser uno lo que es de suyo, medirse y pesarse a sí mismo con medidas y pesos personales [...]" (p. 153); y en Así habló Zaratustra (1978) describe al hombre como "simultáneamente la pesa, la balanza y el pesador" (p. 120).

En Schopenhauer como educador (2000b), Nietzsche comprende al hombre como conjunto de fuerzas, imagen que se corresponde con la idea de la educación como formación cultural que no se concentra en un aspecto de lo humano (por ejemplo en un talento identificado por el profesor) descartando otros:

El filósofo educador con el que yo soñaba probablemente no se contentaría con descubrir la fuerza central, sino que sabría evitar también que pasara a ejercer una influencia destructora sobre las otras fuerzas. Conformar y transformar el hombre entero en un sistema solar y planetario vivo y móvil, reconociendo la ley de su mecánica superior, ésa era la tarea, tal como yo me la imaginaba, de su educación. (p. 31)

Para Nietzsche, la situación del hombre con la cultura es permanentemente conflictiva. La fuerza de lo colectivo, de lo estable y uniforme, hace resistencia a lo singular, lo fluido y diferente, y a lo creativo. La educación, dentro del contexto de la cultura de la máquina, ha favorecido el crecimiento de las primeras en detrimento de las últimas. El llamado a la educación es a que se ocupe de la liberación de estas fuerzas que permitan al hombre la configuración de su propia vida con base en la crítica y la creatividad. Pero la función emancipadora de la educación se da, como veremos, precisamente a partir de una nueva imagen del cuerpo, que en el caso de Nietzsche es concebido en relación con el concepto de voluntad de poder.

\section{Cuerpo $^{1}$ y educación}

El cuerpo como voluntad de poder posee realmente los atributos que la metafísica reservaba al alma, es decir, el cuerpo piensa, elige, juzga, interpreta, crea valores, siente, imagina, de tal manera que todas las formaciones orgánicas participan del pensamiento, del sentimiento y de la voluntad. Lo que pretende Nietzsche es provocar un giro en la jerarquía tradicional en la concepción del hombre. Esto significa revalorar la posición inferior que el cuerpo ha tenido respecto al alma o la conciencia.

Previamente a esta imagen, en Así habló Zaratustra (1978), Nietzsche propone otra imagen del cuerpo que servirá de base a lo que luego será el concepto de voluntad de poder. "El cuerpo es una gran razón, una pluralidad dotada de un único sentido, una guerra y una paz, un rebaño y un pastor" (p. 64). La conciencia, la mente o el alma caen de su estatuto primario, al ser el cuerpo quien los construye a partir de la experiencia. Permeado por ella, el cuerpo, como gran razón, escucha y busca su propio engrandecimiento. Él determina la conciencia que, sabemos, aparece como lo más tardío.

Decimos que el cuerpo es un fenómeno sujeto a una pluralidad de sentidos. El sentido de una cosa es la relación entre esta cosa y la fuerza que la posee. Por eso el cuerpo tiene una historia. La historia de los diferentes sentidos, de las diferentes fuerzas que se han apropiado de él. Lo que importa es el papel que ha jugado y las escenas en que ha participado el cuerpo. Cualquier fenómeno ha sido objeto de múltiples sentidos. Por ello no buscaremos el "origen" del cuerpo, la esencia del cuerpo, ni una definición de cuerpo. Lo que buscaremos es el sentido, y el sentido siempre es plural por ser un conjunto de sucesiones y coexistencias

El cuerpo es "pluralidad" en tanto cada experiencia viene a hacer otro cuerpo. En cada afecto el cuerpo se reconfigura, deviene en otra cosa. Un ejemplo son las tres transformaciones del hombre en camello, león y niño que Nietzsche nos presenta en Así habló Zaratustra. Lo que no se debe entender como una fórmula o evolución lineal del hombre hacia su más alto estadio.

1 Alfredo Rocha de la Torre (2000, p. 164) afirma que Nietzsche utiliza prioritariamente en sus textos el término alemán Leib para referirse al cuerpo, y no tanto el de Körper, que hace referencia al cuerpo anatómico u objetivo. 
El cuerpo pasa por diferentes estados que le dan una nueva dirección.

Ahora, volviendo a la imagen de cuerpo como voluntad de poder, podemos decir que ella se caracteriza por la duplicidad mando-obediencia. Dentro de un mismo cuerpo y entre diferentes cuerpos se hallan relaciones de este tipo. Lo que determina el mando y la obediencia es el estado de fuerza o debilidad. La obediencia por debilidad se expresa en un movimiento del cuerpo hacia la unidad. El mando por el estado de fuerza se hace evidente en un movimiento del cuerpo hacia la variedad, la diferencia, la disgregación.

El más débil se adhiere al más fuerte para sus necesidades de nutrición; quiere cobijarse bajo aquel, hacerse en lo posible una misma cosa con el más fuerte. El más fuerte, por el contrario, se defiende de sí mismo, no quiere perecer de tal manera; antes bien, al crecer, se escinde en dos o más seres. (Nietzsche, 2005c, p. 435)

La unidad se evidencia en un ámbito como la educación, a través de la tendencia a nivelar a los hombres, de desarrollar en ellos una sola cualidad y de truncar su devenir. Esto implica el desconocimiento de diferentes morales, verdades o principios, al creer en una verdad absoluta, única y universal. La verdad absoluta, a la que Nietzsche conceptualizará como "voluntad de verdad", dificulta el cambio, la mudanza de valores y prácticas.

La variedad, la diferencia, la disgregación, por otro lado, se evidencian en el hombre que tiene un sentido relacional. En su camino se hallan a disposición diferentes ámbitos puestos en relación, diferentes perspectivas, diferentes épocas. Un espacio poblado por multiplicidades (la filosofía, la ciencia, la psicología, el arte, la educación, la historia, la moral, etc.,) que atraviesan al hombre haciéndole devenir, en tanto cada encuentro con estas perspectivas viene a configurar un cuerpo distinto.

En Más allá del bien y del mal (1997) se puede leer la función de la educación asociada a una lógica de la diferencia:

Acaso para la educación del verdadero filósofo se necesite que él mismo haya estado alguna vez también en todos esos niveles en los que permanecen, en los que tienen que permanecer sus servidores, los trabajadores científicos de la filosofía; él mismo tiene que haber sido tal vez crítico y escéptico y dogmático e historiador $\mathrm{y}$, además, poeta $\mathrm{y}$ coleccionista y viajero y adivinador de enigmas y moralista y vidente y 'espíritu libre' y casi todas las cosas, a fin de recorrer el círculo entero de los valores y de los sentimientos valorativos y a fin de poder mirar con muchos ojos y conciencias, desde la altura hacia toda lejanía, desde la profundidad hacia toda altura, desde el rincón hacia toda amplitud. (p. 166)

\section{Lectura y escritura}

En la interpretación del autor alemán surgen dos componentes comunes al ámbito de la educación, los cuales pueden generar efectos transformadores sobre el cuerpo del estudiante: la lectura y la escritura. Pero esta empresa puede llevarse a cabo si ambos ejercicios son impulsados por una necesidad de cambio, a partir de una pasión por la configuración creativa de la vida. Tanto la lectura como la escritura se convierten en líneas de horizonte a partir de la cual se elabora una cotidianidad más cercana al performance que a la competencia.

Para Nietzsche, la educación debe formar un gusto por la lectura, caracterizado por una apertura cuyas resonancias se hacen sentir en la reconfiguración del propio cuerpo del lector. Esto, más que una idea, es una experiencia del propio autor. En Ecce homo (2008) Nietzsche afirma su interés por un especial tipo de lectura "recreativa", aquella que lo aleje de sí, que lo cuide de su seriedad.

En mi caso toda lectura forma parte de mis recreaciones: en consecuencia, forma parte de aquello que me libera a mí de mí, que me permite ir a pasear por ciencias y almas extrañas, -cosa que yo no tomo ya en serio. La lectura me recrea precisamente de mi seriedad. (p. 47)

La lectura es una mirada para fundar otra mirada. $\mathrm{Su}$ posición es más cercana a la experiencia que a la memorización. El sentido de esta formación no es el utilitarismo o la producción en serie como lo ha entendido el Estado y por extensión, la universidad. "Quizá el arte de la educación no sea otro que el arte de hacer que cada uno llegue hasta sí mismo, hasta su propia altura, hasta la mejor de sus posibilidades. Algo, desde luego, que no se puede hacer al modo técnico ni al modo masivo" (Larrosa, 1996, p. 259).

La formación así entendida busca la tríada lectura-herida-transformación. La formación del gusto dispone 
diferentes lecturas para crear una atmósfera alrededor del estudiante. El miedo y el dolor ante lo desconocido, la incertidumbre que siempre aparece ante un territorio inédito y problemático. Esta atmósfera busca herir, vulnerar su situación actual. "[...] el deber del educador es causarle heridas o aprovechar las que le cause el destino, y cuando así el dolor y la necesidad hayan nacido, pueda haber en los puntos dañados inoculación de algo nuevo y noble" (Nietzsche, 2005b, p. 170).

Por otro lado, la escritura también puede considerarse un ejercicio para llevar a cabo transformaciones corporales. A nivel personal, la escritura de su propia vida, que inicia a partir de los 13 años, conlleva a una experiencia importante: la experiencia de la propia fragmentación. Lo que le anima no es el enamoramiento de sí ni el sentirse alguien problemático. Quien así escribe no logra algo importante: generar la debida distancia frente a sí mismo.

El que escribe sobre 'sí' es aquel a quien la distinción entre 'yo' y 'sí mismo' le da algo que pensar. Eso no sucede siempre ni en todos. Tiene que estar en juego la curiosidad, un pensamiento exuberante, el enamoramiento de sí y la enemistad consigo; tiene que haber habido rupturas, euforias y desesperaciones, que favorecen o promueven la propia separación de lo indivisible, la división del individuo". (Safranski, 2001, p. 25)

Por ejemplo, la lectura de Lord Byron lo entusiasmó por la capacidad artística con que él rodeaba su vida, una vida escenificada transformada en obra de arte. Nietzsche decidió empeñarse en ver la propia vida con ojos de artista. A través de su imaginación, ejerció la escritura probando personajes. En alguna ocasión ensayó con un cínico nihilista que sufre de exceso de transparencia, alguien que dice ¡conocerse por completo! Pero debido a que Nietzsche seguía siendo un misterio para sí mismo, detuvo la empresa a tiempo. "El joven Nietzsche, que en el escenario interior de los diarios quiere conferir significación a la propia vida, admira a aquellos genios que supieron convertirse en dramaturgos, en autores de su propia vida, no solo hacia dentro, sino también para el público" (Safranski, 2001, p. 35).

Nietzsche dedica gran esfuerzo en la composición de su Ecce homo. Es de gran interés conocer los títulos que se habían sugerido para esta obra porque resaltan la conciencia de la fragmentación o el distanciamiento frente a la lógica de la identidad. Los títulos son los siguientes: "Ecce homo. Anotaciones de un hombre múltiple. 1. Habla el psicólogo. 2. Habla el filósofo. 3. Habla el poeta. 4. Habla el amante de la música. 5. Habla el escritor. 6. Habla el educador" (Nietzsche, 2008, p. 9).

Remitiéndonos a otra obra, Nietzsche considera que el regalo más importante que se le ha otorgado a la humanidad hasta ahora es el personaje al que le dio vida después de 18 meses de embarazo: Zaratustra. Para ello tuvo Nietzsche que habitar los lugares dignos de su personaje, lugares elevados, no sin experimentar él mismo los efectos de su proceso de creación:

Muchos escondidos rincones y alturas del paisaje de Niza se hallan santificados para mí por instantes inolvidables; aquel pasaje decisivo que lleva el título 'De tablas viejas y nuevas' fue compuesto durante la fatigosísima subida desde la estación al maravilloso y morisco nido de águilas que es Eza -la agilidad muscular era siempre máxima en mí cuando la fuerza creadora fluía de manera más abundante. El cuerpo está entusiasmado: dejemos fuera el 'alma'... A menudo la gente podía verme bailar; sin noción siquiera de cansancio podía yo caminar entonces siete, ocho horas por los montes. Dormía bien, reía mucho, poseía una robustez y una paciencia perfectas. (Nietzsche, 2008, p. 109)

\section{Visión dionisíaca de la educación}

El nacimiento de la tragedia (2000a) es el primer libro que escribe Nietzsche cuando era ya catedrático de Filología en la Universidad de Basilea. En el texto, la importancia del arte se halla en función de la vida. De hecho, se entiende la tragedia como metáfora de la existencia en tanto allí evidenciamos la relación del hombre con esta. Los griegos, que habían experimentado los horrores de la vida, precisaron del arte como soporte de su existencia. La tragedia hizo perceptible las fuerzas elementales del universo bajo la apariencia de los dioses Apolo y Dionisos.

Debido al interés de este artículo por abordar la transformación, nos concentraremos en el segundo de estos dos dioses. Dionisos hace experimentar al hombre aspectos como la alteridad en plena vida cotidiana, haciéndole saltar la barrera de las identidades fijas. "Ya en el proceso dionisíaco el artista ha abandonado su subjetividad" (Nietzsche, 2000, p. 65).

Él se manifiesta en la metamorfosis, el disfraz y la máscara, logrando así que quien lo acoja se convierta en otro. Dionisos borra los límites, desborda la forma. 
Quien lo experimenta pone en duda las categorías que lo polarizan: joven/viejo, masculino/femenino, salvaje/civilizado. "Alteridad radical también en el caso del poseído por Dioniso [...]: la posesión dionisiaca desemboca en un universo gozoso en el que se anulan los ajustados límites de la condición humana" (Vernant y Vidal, 2002, p. 45). Pero se debe advertir que una condición de la alteridad es la capacidad para no tomarse en serio a sí mismo, algo que señalamos anteriormente. En esto consiste la prueba dionisiaca, en el gusto por la ambigüedad, por la paradoja, y por la risa irónica dirigida contra sí mismo, que nos despoja de una pretensión absoluta de seriedad. "Un dios en el que queremos creer seriamente al menos no debería ser irónico. Sin embargo, Dionisos no se caracteriza por tener buenas intenciones con los más serios de sus creyentes" (Sloterdijk, 2000, p. 110).

\section{Conclusión}

De acuerdo a lo anterior, se insinúa la siguiente reflexión a partir de la interpretación de las concepciones de cuerpo y educación en la obra de Nietzsche. Frente al problema actual de la pasividad, el deseo de producción, eficacia, estandarización y paralización de las identidades mediante perfiles laborales que caracteriza la formación universitaria, se propone un proceso de creación de personajes pedagógicos ${ }^{2}$ como alternativa para la formación docente.

La idea de extrapolar procesos de creación más relacionados al mundo artístico que al educativo, se puede considerar como un acto de resistencia contra el efecto desencadenado por la producción industrial, el cual pretende reducir el trabajo humano a la repetición de gestos inmutables. Cuando un educador, graduado o en formación, se vincula en un proceso de creación de su propio rol docente, empieza a aislarse de procesos estandarizados y, por lo tanto, adopta una postura activa frente al diseño de su profesión que también pone en juego la propia existencia. Es bien sabido cómo la cultura actual sigue fomentando la homogenización de las identidades, potenciando las identidades públicas más pasivas (trabajadores, consumidores, votantes, contribuyentes). Así, en el campo docente, los perfiles laborales ordinariamente vienen dados desde afuera (políticas, planes de formación, guías curriculares).

2 Debemos aclarar que proporcionar detalles acerca de un proceso de creación de personajes exige un espacio más amplio que el proporcionado en este artículo.
¿Qué significa la categoría de personaje pedagógico desde Nietzsche? En general, un personaje es el producto de un proceso de creación artístico, tanto en el teatro como en la literatura, la pintura e incluso la publicidad, y se halla enmarcado dentro de los límites de la obra. Sin embargo, en la propuesta, el personaje pedagógico se circunscribe al docente o estudiante aspirante a licenciarse, que en escena (el aula por ejemplo) encarna físicamente un personaje que ha sido creado por él, con una intención educativa y, tal vez, estética.

Él surge a partir de una investigación artística que se apoya en la percepción de la realidad, de lo cotidiano y de todo aquello que le dé vida sin importar su procedencia. Por ejemplo, se pueden incluir entrevistas a personas claves, lecturas de diarios, videos, películas, viajes y situaciones peculiares que ocurran incluso en el ámbito cotidiano y que contribuyan a la singularidad del personaje. El mundo fuera de la academia no está vetado al proceso de creación. Así, el personaje es creado a partir de un conjunto de componentes como: el contexto (geográfico, social, educativo, religioso...), la descripción física, su psicología, los valores, las emociones y actitudes (Seger, 2000).

Este proceso se corresponde con la idea que Nietzsche posee de la educación: ella es el lugar donde el cuerpo experimenta una serie de transformaciones a partir de la vivencia de lo diferente. Así, cuando se crea y encarna un personaje con una intención pedagógica, lo que debe experimentarse, antes que nada, es una situación de alteridad. Frente a la lógica de la identidad del educador y de la unidad de criterios de un colectivo docente, la construcción de personajes implica una sensación de extrañamiento, de desfamiliarización. Es un mecanismo para tomar distancia frente a uno mismo y así experimentar otro lenguaje. "De este modo los personajes conceptuales son los verdaderos agentes de enunciación. ¿Quién es yo?, siempre es una tercera persona" (Deleuze y Guattari, 1994, p. 66).

Sumado a esto, la creación del personaje exige, antes que nada, la superación de los estereotipos, que a su vez conlleva a una confrontación con los prejuicios del docente. La construcción parte de una exploración personal de un territorio nuevo. A partir de la curiosidad, el docente se involucra en una aventura, una búsqueda que conlleva al descubrimiento de mundos y personas diferentes. La curiosidad es el motor que permite interesarse en detalles que otros ignoran, y que van a acoplarse poco a poco a su personaje. Una observación que calle su propia cultura y se permita indagar en lo diferente puede 
ser útil para construir un personaje que no pertenezca a los lugares comunes. De hecho, la importancia de superar los estereotipos y nuestros prejuicios radica en que construimos personajes que son capaces de hacer lo que nosotros no somos capaces de hacer. De ahí que el personaje no sea el seudónimo del autor sino su heterónimo.

Un gran personaje novelesco tiene que ser un Original, un Único, decía Melville [...] Cuando Nietzsche construía el concepto de 'mala conciencia', podía ver en él lo más repulsivo del mundo, pero no por ello dejaba de exclamar: jaquí es donde el hombre empieza a hacerse interesante!, y opinaba en efecto que acababa de crear un concepto nuevo para el hombre, que convenía al hombre, en relación con un personaje conceptual nuevo (el sacerdote) [...]. (Deleuze y Guattari, 1994, p. 84)

Efectivamente, Nietzsche llevó a cabo su propia fragmentación como sujeto a través de la creación de personajes conceptuales. Al construirlos, logró ejecutar los movimientos más superlativos de su filosofía: danzar, volar, apreciar, destruir, conquistar. "Invocamos a Nietzsche porque muy pocos son los filósofos que han trabajado tanto con personajes conceptuales, simpáticos (Dioniso, Zaratustra) o antipáticos (Cristo, el sacerdote, los Hombres, el propio Sócrates, antipático ahora...)" (Deleuze y Guattari, 1994, p. 66).

Por lo tanto, construir personajes pedagógicos es lo mismo que construir cuerpo, hacer cuerpo, llegar a ser otro: es un hacer que hace ser. Por eso, no es lo mismo un personaje pedagógico que crea conceptos al personaje que solo los expone. "El personaje conceptual no tiene nada que ver con una personificación abstracta, con un símbolo o una alegoría, pues vive, insiste [...]" (Deleuze y Guattari, 1994, p. 66). Experimentar personajes significa actualizar los límites del pensar, del querer, del sentir, en tanto esta despersonalización, más que una patología, implica hacerse a muchos ojos y conciencias que dotarían de múltiples perspectivas al docente vinculado en el proceso.

En síntesis, la creación y experimentación de personajes, con todos sus perfiles psicológicos, sus valores y prácticas, su manera de relacionarse con el mundo, sus necesidades, constituyen una estrategia pedagógica para hacer emerger las fuerzas de creación que ubiquen al docente en situación continua de autotransformación. Y así, como sugerirá Nietzsche, el docente podrá relacionarse con sus estudiantes, promover la transformación de ellos, transmitir conoci- miento y favorecer la producción del mismo, a partir de la experiencia personal de haberse transformado a sí mismo.

\section{REFERENCIAS}

Deleuze, G. y Guattari, F. (1994). Qué es la filosofía (Traducido por Thomas Kauf). Barcelona: Anagrama.

Larrosa, J. (1996). La experiencia de la lectura: estudios sobre literatura y formación. España: Laertes.

Nietzsche, F. (1978). Así habló Zaratustra. (Traducción de Andrés Sánchez Pascual). España: Alianza Editorial.

Nietzsche, F. (1980). Sobre el porvenir de nuestras escuelas. (Traducción de Carlos Manzano). Barcelona: Tusquets Editores.

Nietzsche, F. (1997). Más allá del bien y del mal. (Traducción de Andrés Sánchez Pascual). Madrid: Alianza Editorial.

Nietzsche, F. (2000a). El nacimiento de la tragedia. O Grecia y el pesimismo. (Traducción de Andrés Sánchez Pascual). Madrid: Alianza Editorial.

Nietzsche, F. (2000b). Schopenhauer como educador. (Traducción de Jacobo Muñoz). Madrid: Biblioteca nueva.

Nietzsche, F. (2001). La gaya ciencia. (Traducción de Pedro González Blanco). México: Editores Mexicanos Unidos, S.A.

Nietzsche, F. (2005b). Humano, demasiado humano. (Traducción de Carlos Vergara). Madrid: Edaf.

Nietzsche, F. (2005c). La voluntad de poder. (Traducción de Aníbal Froufe). Madrid: Edaf.

Nietzsche, F. (2008). Ecce homo. Madrid: Alianza Editorial.

Rocha, A. (2000). El cuerpo como centro de interpretación. Una aproximación a la concepción nietzscheana. Universitas Philosophica, Vol. 17, No. 34-35.

Safranski, R. (2001). Nietzsche: historia de su pensamiento. Barcelona: Tusquets Editores.

Seger, L. (2000). Cómo crear personajes inolvidables. Guía práctica para el desarrollo de personajes en cine, televisión, publicidad, novelas y narraciones cortas. España: Paidós.

Sloterdijk, P. (2000). El pensador en escena. El materialismo de Nietzsche. España: Pre-Textos.

Vernant, J. y Vidal-Naquet, P. (2002). Mito y tragedia en la Grecia antigua. Barcelona: Paidós. 